San Jose State University

SJSU ScholarWorks

Faculty Publications

Communication Studies

$11-2012$

\title{
Meeting in the middle: Fred L. Casmir's contributions to the field of intercultural communication
}

Mark C. Hopson

George Mason University

Tabitha B. Hart

San Jose State University, tabitha.hart@sjsu.edu

Gina Castle Bell

Texas Tech University

Follow this and additional works at: https://scholarworks.sjsu.edu/comm_pub

Part of the Communication Commons

\section{Recommended Citation}

Mark C. Hopson, Tabitha B. Hart, and Gina Castle Bell. "Meeting in the middle: Fred L. Casmir's contributions to the field of intercultural communication" International Journal of Intercultural Relations (2012): 789-797. https://doi.org/10.1016/j.ijintrel.2012.08.008

This Article is brought to you for free and open access by the Communication Studies at SJSU ScholarWorks. It has been accepted for inclusion in Faculty Publications by an authorized administrator of SJSU ScholarWorks. For more information, please contact scholarworks@sjsu.edu. 
Meeting in the Middle: An Essay on Fred L. Casmir's Contributions to the Field of Intercultural Communication

Mark C. Hopson, Tabitha Hart, and Gina Castle Bell

Mark C. Hopson, Department of Communication George Mason University, Robinson A 307, 4400

University Drive, MSN 3D6, Fairfax, VA 22030

Tabitha Hart, San Jose State University, Department of Communication Studies

Gina Castle Bell, Department of Communication Studies, Texas Tech University, MS 3083, Mass

Communication Building, Room 264, Lubbock, TX. 79409-3083

Corresponding Author Telephone 704-983-1090

\section{Abstract}

Fred Casmir's third culture building (TCB) framework made a major theoretical contribution to communication studies. Casmir conceptualized the framework as an active process whereby different cultural groups come together to form a third culture between them. The third culture then becomes a common ground for all participants; a cognitive space that incorporates elements of both cultures and yet remains separate and distinct. Third culture building is a departure from adoption (the process of taking on the cultural mores of another) or adaptation (modifying one's cultural mores to better fit those of another), and achieved through deliberate development in an extended process, during which all participants gain an understanding of, and appreciation for, one another. In this essay, the authors review the life and work of Fred Casmir-a leading figure in establishing intercultural communication as specific area of study. Next the authors discuss the ideological foundations, intended use, key applications and heuristic value of Casmir's third culture building framework.

Key words: Fred L. Casmir, oral speech, communication scholarship, third culture building, international communication, intercultural communication, communication and speech organizations

${ }^{*}$ Corresponding author. Tel: +703-993-4414

Email addresses: mhopson@gmu.edu (Mark C. Hopson); home@tabithahart.net (Tabitha Hart); grcbell09@gmail.com (Gina Castle Bell).

\section{Introduction}

In April 1967, Fred L. Casmir (Ph.D., Ohio State University, 1961) traveled from Pepperdine University to Memphis, Tennessee, to meet with the Speech Association of America's Committee for Cooperation with Foreign Universities. The committee's charge included responding to changes taking place at institutions across the nation and strengthening the Association's outreach to scholars at foreign universities. The turbulence of the 1960s had impacted higher education on various levels. Changes taking place within the communication discipline included re-naming the committee's sponsoring organization which, between 1947 and 1969, had been called the Speech Association of America. In 
1970, the organization would become the Speech Communication Association (SCA), and later-in 1997-the National Communication Association (NCA).

While in Memphis, Casmir and fellow committee members found themselves conceptualizing intercultural communication as its own field of study. The idea gained momentum in the summer of 1968, at Pepperdine Haus in Heidelberg, Germany where Casmir helped to organize the first of several biannual German-American mini-conferences on international and intercultural communication. Approximately a dozen scholars attended the first mini-conference, and its impact is remembered today. Michael H. Prosser recalls that his eldest daughter enjoyed her sixth birthday in Heidelberg amidst the scholarly figures who would ultimately contribute to the history of the field.

The mini-conferences energized growing interests regarding the nexus of communication and culture. At the 1970 meeting of the International Communication Association (ICA) in Minneapolis, K. S. Sitaram and others proposed and developed the ICA's Intercultural and Development Communication Division. Primary concerns of the Division included theory and practice of communication between and among different cultures of the world; comparisons of different communication systems in different cultural, national or ethnic groups; and the relationship between communication and national development (http://www.ou.edu/idc/).

In 1971, the Canadian Oral Communication Association, and the International and Intercultural Commission of the Speech Communication Association leaders came together at the Indiana University Conference (Brown County) to undertake objectives to further develop the new field of study. The first order of business was to better establish the content of the field. Second, they thought it necessary to take active steps toward increasing undergraduate and graduate courses in intercultural communication at North American universities. Present at this foundational meeting were Bill Howell, former president of the SCA; Grace Layman of Memorial University of Newfoundland and president of the Canadian Oral Communication Association; Edmund Glenn, former US State Department interpreter; and Edward C. Stewart, former trainer for the Peace Corps. Edmund Glenn and Edward Stewart are often credited with starting one of the first departments of intercultural communication at the University of Rhode Island in 1966. The program was cut shortly afterwards due to budget constraints, but the achievement inspired new ideas about intercultural communication programs. In fact, the graduate students who attended the Indiana University consultation chaired by Prosser-including William J. Starosta, Barbara Monfils, Sherry Ferguson, William Davy, and Iris Gonzalez-would carry these programmatic ideas forward in their own careers. The participants agreed that both objectives (content and process) required academic articles, journals and books on the subject, as well as homes for these materials across various communication associations. Fred L. Casmir was commissioned to become the first editor of the SCA journal, International and Intercultural Communication Annual, a position he held between 197 and 1976.

In 1973, Prosser chaired a meeting at the University of Virginia (Massanetta Springs) to develop syllabi in intercultural communication and social change (Prosser, 1973, 1974). In 1974, Casmir and Prosser crossed paths again at national communication conferences and the Speech Communication Association, International Communication Association, and Society for Intercultural Education, Training and Research 
Summer Conference. Nemi C. Jain, who succeeded Casmir as editor of the IICA, Prosser, and Melvin Miller prepared the SCA Proceedings of that conference, which utilized Edward C. Stewart's "Outline of Intercultural Communication" as a guide for developing the field (Jain, Prosser \& Miller, 1974).

\section{Casmir's Personal History}

Casmir contributed to efforts to establish the International and Intercultural Communication Division of what is now the National Communication Association. He also helped form the Intercultural and Development Communication Division of the International Communication Association, and was an early leader in the International Society for Intercultural Education, Training, and Research (SIETAR International). Today Casmir lives in Northern Arizona, where he works at Northern Arizona University with campus ministry in the Church of Christ and as a docent at the local museum. His legacy continues to inspire scholars of the next generation, partially due to its potential for heurism. He is an author, teacher and organizer.

[Fred Casmir] was born in 1928 and grew up in pre-World War II Germany. Drafted into the Nazi Youth Core, he escaped conformity to Nazi ideologies by fleeing to the Danish border and converting to Christianity. Casmir began his forty-two-year teaching career at Pepperdine University in 1957. He taught a variety of communication courses including international studies, intercultural communication and advanced communication theory. (http://graphic.pepperdine.edu/news/2002/2002-01-24profcontinuesrecovery.htm). Casmir had been a minor leader in the Hitler Youth and experienced firsthand the WWII bombings of his hometown of Berlin As a teen he volunteered for the Air Force (Luftwaffe) and was accepted as an officer's cadet (Offiziersanwaerter). Immediately following his 16th birthday o December 30,1944, Casmir was called u to become part of a ground-force infantry unit and was thrown into the horrible final months of fighting against Russia, just east of Berlin. He ended up near the Danish border just before May 8th, when the war ended with Germany's surrender.

Casmir's personal experience in the Nazi horror may have shaped his commitment to the study of international politics. He completed his high school education in 1948, in Berlin and Frankfurt, Germany. He earned a PhD in speech in 1961 from Ohio State University, where he completed his dissertation titled "Hitler: A Study in Persuasion." This attention to global conflict continued throughout Casmir's career, as is evident in the edited volumes (1995) Communication in Eastern Europe: The Role of History, Culture and Media in Contemporary Conflicts and (1997a) Ethics in International Communication.

Casmir's early publications also proved to be important resources for developing intercultural communication programs, such as his (1973) "International, Intercultural Communication: An Annotated Bibliography." His annuals also featured works which expanded the field of study. For instance, Edward C. Stewart's "Outline of Intercultural Communication" was a central part of Casmir's (1978) International and Intercultural Communication. The "Outline" had served as the study guide for the 20 participants in the 1974 Chicago meeting sponsored by SCA, ICA, and SIETAR International. Originally designed under the authorship of Stewart, and including contributions by members of the earlier conferences, "Outline of Intercultural Communication" was one of the first US publications to define the field, delineate topics for presentation, and furnish a general sketch of its future development. In creating the outline, Stewart 
and fellow committee members sought to achieve cultural objectivity by inviting participation from representatives of various societies. Contents of the "Outline" represented a theoretical analysis of intercultural communication, a review of its empirical accomplishments, and a forecast for the future of intercultural communication.

Certainly Casmir has been a diligent scholar. He has authored over sixty articles, and twenty books and annuals. Over the course of his career, he was involved with the German Speech Association, Speech Communication Association (later the National Communication Association) the International Communication Association, SIETAR International, Pi Kappa Delta, and the World Communication Association. His awards include Outstanding Faculty Advisor (1986), Fellow, Irvine Foundation Grant (1993), Distinguished Professor, Seaver College (1994 - 1999), Teacher of the Year (1995), and Distinguished Professor Emeritus, of Communication at Pepperdine University (1999).

In the early 1980s, Casmir was among the first US communication professors to teach in Shanghai, China after its 1978 "Opening Up" policy. He joined Prosser in Beijing, China in 2002 as an invited guest o China Central TV's International Channel, "Dialogue," for a conversation about the nature of intercultural communication, hosted by the program director, Yang Rui. During the Reagan administration, Casmir was considered for an appointed membership in the US Federal Communications Commission. Additionally, he continued to make myriad programmatic contributions at Pepperdine University, including the development of the institution's International Studies Program and its public relations major. These programs stand today in part as a testament to Casmir's vision. Kathie Johnson, a former student, remembers him with appreciation: "If you demonstrated to him a drive and commitment to fight for knowledge, the rewards you would reap from him and his classes were overwhelmingly wonderful. There are things that I learned from Fred Casmir's communication theory class that I still apply to my life every day. He gave me amazing guidance and insight that helped me in my doctoral program and in my career." (http://graphic.pepperdine.edu/news/2002/2002-01-24profcontinuesrecovery.htm)

After retiring in 1999, Casmir and his wife Mina relocated to Flagstaff, Arizona. They became involved in the Northern Arizona Church of Christ, where he served as chairman of the Campus/College Age Ministry, where he teaches Bible study class. Clearly, he has always been teacher at heart. "I like the idea of working with young people at an intellectual level," Casmir told the Graphic in January, 1999. "I enjoy the stimulation and exchange. There has always been something new to keep me involved, growing and excited" (http://graphic.pepperdine.edu/news/2002/2002-01-24profcontinuesrecovery.htm). Casmir's work exemplifies the value of intercultural communication studies. His legacy continues to impact a new generation of scholars. The following section examines his most popular theoretical perspective.

\section{Major Theoretical Contribution: Third culture Building}

The third culture building (TCB) framework is Fred Casmir's major theoretical contribution to communication studies. Here, we describe the TCB framework, including its ideological foundations, intended use, and key applications. As an emerging scholar, Casmir saw substantial shortcomings to the 
intercultural communication models of the 1960s and early 1970s. First, too many theories concentrated on generating and testing cultural comparisons with the goal of creating a complete catalogue of cultural attitudes, behaviors, and norms. Such catalogues, he reasoned, inevitably led to broad and often inaccurate generalizations about nations and nationalities. Furthermore, such catalogues could never be nuanced or detailed enough to cover the myriad types of intercultural communication situations. Casmir critiqued this approach for remaining within the realm of the hypothetical, since it could not adequately explain how people would actually interact with others in real life. Ideally, he felt that scholarship should focus on lived intercultural communication processes rather than hypothetical situations. Casmir's (1978) research reflected on the type of intercultural communication model he envisioned: "I am advocating the conscious development of a multi-cultural systems-construct applicable to specific communicative interaction. It appears to me that this would allow us to see the communication process more readily as something different from, or consisting of more than its original component parts. It becomes something based upon and contributed to by both original and new factor-combinations, a kind of situational subculture developed through the interaction of its members. The approach discussed here may prevent us from assuming that we can understand common communicative-process-functions by studying the original, individual culture and nationalcompound parts of any communication system in their pristine states. It forces us, in each instance, to start with a new, situational, systems-model for what may be a significantly different situation, created by the interaction of all contributing parts. It can also prevent the unwarranted and seductive conclusion that we have discovered the underlying rules of the total game, rather than gaining some limited, specific, insights" (p. 250).

Next, Casmir noted a failure to sufficiently address the imbalance in power and privilege inherent in intercultural communication situations. His publications highlight the tendency of the privileged (whether they enjoyed their status by virtue of their gender, nationality, race, or otherwise) to use communication as a means of manipulating, forcing, or otherwise taking advantage of persons in less powerful positions. Casmir saw the promotion of cooperation, sensitivity, and receptivity to the needs, desires, and ways of one's communication partners as the primary goals of scholarship. At the same time, he knew that strategies for total adaptation are never viable solutions to intercultural power imbalances. Instead there is a need for a more equitable middle ground.

Casmir encouraged scholars to acknowledge the diversity of communication habits, preferences and modes, and needs and interests. Moving forward requires practical tools. Even more, Casmir thought that intercultural communication scholarship should, ultimately, help people produce cooperative, productive, and egalitarian communication, to the extent that all attain beneficial outcomes. It was in this spirit that Casmir conceived and refined the TCB framework. The third culture building framework is practical in two important ways. First, it is intended for real-world situations; that is, TCB can be employed by practitioners - not just scholars - of intercultural communication. Second, the TCB framework is intended to be feasible and well suited for assorted situations. Practitioners do not necessarily have the time or resources to conduct lengthy research into a communication partner's backgrounds, styles, and histories. As such, the principles of TCB work well for lay-persons interested in planning and evaluating intercultural communication situations. Third culture building may be defined 
as process by which different cultural groups come together to form a third culture between them. This new culture becomes the common ground for all participants; sort of cognitive space that incorporates elements of both cultures and yet remains separate and distinct. In this sense, third culture building is a departure from adoption (the process of taking o the cultural mores of another) or adaptation (modifying one's cultural mores to better fit those of another). Third cultures are achieved through deliberate development in an extended process, during which all participants gain an understanding of, and appreciation for, others while negotiating purposes, standards, methods, goals and eventual satisfaction in dialogic, conversational setting (Simon \& Baxter, 1993).

TCB is not based solely on an attempt to achieve outcomes desired by all participants, but includes a shared development of standards and methods for achieving those ends. The new interactive relationship which evolves would represent an expression of mutuality, one which can be understood, supported and defended by all who share in its development: The purpose is "to achieve lasting, not merely momentary, maximum adaptation and survival in a framework designed and used by all of its participants" (Casmir, 1999, p. 108). TCB is achieved through dialogue between all the key parties. It can never be one-sided, but rather "involves mutual learning, a cooperative dialogue and building experience rather than one-sided attempt to be politically correct, or to simply assimilate" (Casmir \& Muir-Packman, 1999, p. 485). All sides must take part and everyone must "[adjust or even forfeit] extant cultural norms and values [so that a new culture can be developed] where dialogue can freely exist and which is seen as beneficial to all of those involved" (Casmir \& Muir-Packman, 1999, p. 486).

To engage in the process of third culture building, communication participants go through a series of steps (with likely reiterations) suggested by the model. These steps include making contact with the communication partner; acknowledging a mutual need for cooperation; gathering information about one another; reflecting o one's own outlook, needs, values, ethics, and standards; reflecting o how one's own outlook, needs, values, ethics, and standards can be integrated with those of the communication partner; negotiating, creating, testing, and modifying one's approaches; bringing it all together; and, finally, (re)negotiating both the communication and the relationship with the partner (Casmir, 1993, 1994). These steps, Casmir asserted, emphasize eight primary qualities, which are central to the study and practice of communication between cultural beings.

\section{Eight Primary Qualities of TCB}

There are eight primary qualities of the third culture building framework. The description here is not exhaustive; rather, we focus on key qualities as emphasized throughout Casmir's discussion of TCB.

First, TCB is an organic "bottom up" and emergent practice in that participants transform their resources (cognitive frameworks and beliefs) for purposes of making something constructive (Casmir, 1993, p. 408). Instead of trying to fit our communication partners and/or their approaches into a-priori categories, we move forward together building new definitions and realities. The situation specific framework can then be used to co-create interactional environments that are relevant for each (new) real life communication scenario, which take into account the particularities, influences, affordances, constraints, etc. of a given situation (Casmir, 1997b). As such, third culture building can be described as 
"creative and innovative endeavor" which results in something new (a third culture) that did not previously exist (Casmir \& Muir-Packman, 1999, p. 484).

Second, third culture building is focused o a process, and provides users with a general framework for engaging in communication (Casmir, 1997b). Put differently, TCB seeks to help people work together, make sense of one another, interpret one another's communication behaviors, and establish common grounds. Participants are required to be attentive to the process and any changes that may occur (Casmir, 1999).

Third, TCB is an egalitarian approach rooted in the ideals of fairness and democracy. All participants are viewed as equals and all are expected to collectively foster "a climate of care, concern, and mutual respect, rather than confrontation based on persuasion paradigms that require submission by some and domination by others" (Casmir, 1991, p. 233). The needs of all parties are taken into account, and no one's needs should have greater priority over another. According to Casmir (1993), TCB involves equitable communication: [TCB] tends to avoid the application of absolute, predetermined, culturally dictated rules of logic and reasoning that are assumed to result in listeners' acceptance of arguments. The speaker/listener dichotomy is replaced by an interactive, mutually beneficial creative process that does not necessarily depend o 'equal' contributions from the involved partners. Rather, it finds its meaning in contributions determined by and valued because of mutually agreed-upon needs. (p. 419420)

Fourth, TCB requires self-knowledge and/or self-discovery, and knowledge of one's communication partner. There is a "willingness of participants to first understand themselves, their own background, needs, or even their lack of awareness or naïveté. It requires a kind of growing together" as participants discover and negotiate how they can best work together (Casmir, 1978, p. 252).

Fifth, TCB is both conscious and deliberate. It is not something that can be done passively, nor is it something that happens by chance. Casmir describes consciousness in this way: [It is the] development of mutually accepted, non-coercive structures, organizations, value systems, artifacts, and other aspects of culture ... as a deliberate communication effort, over time, by all those involved in developing the bases for future trust, respect, and meaningful interactions. (Casmir, 1991, p. 7).Consciousness, as it relates to TCB, implies the mutual effort of all parties involved in the process. One party cannot create a third culture. Instead, all participants share in its creation. This is consistent with Casmir's (1991) value for a dialogic process that calls for a conscious effort to build the future together: "That does not mean that some sort of contribution arbitrarily defined as equal is required of all participants. Rather, the standard ought to be mutually defined needs mutually met" (p. 233). A third culture can only develop through rigorous and open communication. The new interactive relationship works to represent an expression of mutuality to be understood, supported and defended by all who shared in its development.

Sixth, TCB is based in proactive action. Communicators can avoid problems, conflicts, and crises by initiating a cooperative, problem-solving approach to communication. This is a framework for treating people as agential forces in order to recreate the potential for healthy interactions (Casmir, 1997b, 
1999). This view is in direct contrast to other theories that define culture as an overriding force that programs us to behave in certain ways. Culture is ever-present, but does not necessarily predestine us to act any particular way. Rather, we have the power and the ability to reason and modify cultural behaviors: What is important to the third culture building model, however, is the fact that culture does not create an overbearing influence resulting in simple stimulus-response situations. Culture itself is seen here as a process not as a static object. In that culture-as-process environment human beings decide, frequently, how to respond and adapt. ... Between two or more human beings from different backgrounds, within one culture or between more than one, it must frequently be decided how to approach that adaptation, whether or not and how to use change or discard existing cultural models or systems. Over time and between those whose physical, emotional or intellectual survival is seen as being at stake, that process continues (Casmir, 1997b, p. 111).

Seventh, TCB framework imagines possibilities for positive outcomes. Its intention is to see all manners of producing results, which are mutually beneficial and maximally satisfactory to all parties taking part in its creation. These results should be relatively durable. In this way, TCB may be described as a future oriented model of communication that envisages potentialities for participants, including the potential to create, innovate, build, and hold positive outcomes, or shift one's frameworks (Casmir, 1993, 1999). However, TCB does not advocate any particular outcomes, except that they should be agreeable and fit all needs and situations.

Eighth, TCB requires time. This is not a quick fix to any intercultural scenario, but demands the slow and deliberate reflection, information seeking, innovation and practice of its participants. As long as the intercultural contact continues, so too does the process of TCB. Participants in the scenario never say to one another, "That's it - we have completed our third culture." Rather, TCB should continue as long as people continue their intercultural contact. Ideally, TCB "achieve[s] lasting - not merely momentarymaximum adaptation and survival in a framework designed and used by its participants" (Casmir, 1997b, pp. 109-110), regardless of whether third cultures "become permanent or [remain] relatively short-term 'communication cultures'" (Casmir, 1991, p. 7).

\section{Creative Applications}

Casmir saw a need to examine the difference between mutuality and dominance as a model for human survival. In the early 1980s, his attention turned to phenomenology and hermeneutics, which further enhanced the researcher's value for lived experience in intercultural and international interactions. Casmir's (1984) article "Communication and Development Alternatives: Foundation for Policy Implementation Designed to Meet Development Needs of Third-World Nations" was published for and utilized by the US Department of State. Emphasizing perceptions of the cultural "Other," Casmir articulated challenges and strategies for the development of impoverished countries, and called for efforts to 1) transform government officials' perceptions of various ethnic groups, and 2) alter officials' intercultural and cross-cultural interactions with various ethnic groups.

Scholars continue to draw from Casmir's ideas. Disciplines such as public relations (Bardhan, 2011) and identity management theory (P. W. Lee, 2006) have picked up and extended TCB. For example, S. Lee 
(2006) developed a survey tool for the quantitative measurement of third culture building in intercultural marriages. Another popular account is Casmir and Muir-Packman's (1999) analysis of the Disney Corporation's attempt to export its organizational system to a new cultural setting in Paris, France. Disney's effort was severely challenged for lack of TCB. Casmir and Muir-Packman's analysis revealed the social and economic risks to merely transporting cultural values, and demonstrated the greater need to create cultural and responsible values based on the needs of all involved. Undoubtedly, various aspects of global business, healthcare, and education stand to benefit from the qualities of third culture building. Conversely, social and global life can also be hindered by the lack thereof.

Perhaps more than anything else, Casmir contributed to key philosophical and methodological foundations in intercultural communication research, calling for "a paradigm shift for international and intercultural communication research" (Casmir, 1993, p. 407). The foundations of the paradigm shift are explored in the final section.

\section{Concluding Philosophical Contributions}

Communication shapes our lived experiences. Casmir saw it as a life and death issue, writing that communication is a "major human survival tool" (Casmir, 1976, p. 1). From this perspective, individuals engage as systems--open, biological, and metabolic-which depend o communication in order to exist. Casmir explored how people experience difficulty when interacting with individuals from different cultures and/or nations. The solution, he suggested, is to manage conflicting perceptions of difference. Management occurs in part by creating another level of ethical interaction wherein humans can adapt and contribute. Perhaps his lived experiences enabled Casmir to see how communication can lead to mutual understanding and tolerance, or hostility and war. His contributions to the work of other scholars, writers and practitioners of intercultural ethics led to many articles and books on the concept.

In addition to positioning communication as vital to human survival, Casmir (1976) criticized the positivist, behavioral approach to exploring its complexities. He advocated for an alternative model to better understand communicative actions which are not explained fully by biological make-up, and which do not operate strictly from cause and effect. Communication is much too complex for solely causal perspective, especially as it relates to intercultural and cross-cultural contexts. Instead of seeing communication as a response to a stimulus, Casmir (1976) called on scholars to conceptualize it as something more, something that is "continually changing, inventing and reinventing, creating and recreating ... on the basis of underlying rules and codes" (p. 16).

Casmir opposed the idea that the only purpose of communication is to influence others. He argued early on that persuasion is merely one part of larger process based in "rules, codes, and biological, neurological mechanisms" (Casmir, 1976, p. 9). Effective intercultural communication practice is not persuasion, but an effort to understand one's partner and enhance meaningful dialogue. In this way, he advocated for model that emphasized situational, supportive (sub)culture or multicultural systemsconstruct, applicable to specific communication interactions. Ultimately, he challenged us to examine what occurs when "cultures meet and integrate rather than destroy each other" (Casmir Asuncion- 
Lande, 1989, p. 291). In the process of delineating conflict, we learn more about how to develop supportive, healthy communication.

Third culture building moved beyond traditional models of sending and receiving messages. Casmir focused on the original parts of the transaction model, but accounted for original and new factorcombinations or a situational sub-culture developed through interaction of its members. The goal is to prevent interpretations based o information we already know, and "in each instance, start with a basically new model for [determining] what may be a significantly different situation, created in the interaction of all contributing parts" (Casmir, 1976, p. 12). Essentially, the strategy is to avoid making any one culture or nation the criterion for human interaction. Healthy interaction occurs when neither individual nor personal cultures are dominant in the communication context; all persons contribute to the situation in order to communicate effectively.

Perhaps most importantly, Casmir challenged scholars to resist monolithic approaches and to embrace the myriad aspects of difference surrounding the communicative experience. He joined a prolific group of scholars who held fast to the principle of similarities and differences, making it the central focus for study. These scholars found that in some cultures differences is necessary for communication to take place. Therefore, successful communication should not be measured by agreement and conformity, but by the opposite. They found, "It is o the issue of difference, either naturally or by acquisition, that intercultural communication rests its claim for identity" (Prosser, 1978, p. 11). Today "difference matters" is a central theme in the field (Allen, 2011). Casmir's challenge calls for continued observation, exploration, and explanation of that experience-while upholding the value for cultural relativity, safe space, and strategies to avoid forced assumptions.

What is most significant about Casmir's work? His legacy is like the current status of intercultural communication. Like the field itself, Casmir's contributions are appreciated most by those who understand the history and value of intercultural work. On the other hand, intercultural work hardly yields immediate rewards or recognition. As such, a larger vision is required: Casmir helped to frame and strengthen a vision for intercultural communication scholars seeking to make the world a better place. When, in 2011, Casmir was asked to respond to the question of significance, he shared these words: "If anyone were to ask how I would summarize what I attempted to do, it would result in two answers. First of all, I never considered myself to be a second-best sociologist, cultural expert, anthropologist or archaeologist. My roots go deeply into the fertile soil of the rhetorical/speech/communication tradition. As a result, "end-states" never were of great importance to me, which brings me to my second point: Developing my third culture building theory began when I became aware that at least one scholar in another discipline had described third cultures as an end-state, leaving me as a communication scholar to ask myself, How do we get to such an end-state whose existence can be readily identified in history and today? In other words, I have always felt that a process orientation would allow communication scholars to make their most significant contributions. I always saw my calling to be the start of something ... including interactions with those in other disciplines. I had very little interest in getting stuck ... I have always been challenged by my attempts to think and explore, together with those from other backgrounds." 
Thus, for Casmir and scholars coming after him, intercultural communication should establish mutuality, adaptation, understanding, interaction, interdependence, and meaningful participation, if not equality, by all. Put simply, effective intercultural communication requires that we treat one another more humanely, thereby meeting in the middle. After all, communication is in many ways all about coming together as human beings. In this regard, Casmir has contributed to some of the most important work of our time.

References (including all of Casmir's available works)

Allen, B. J. (2011). Difference matters: Communicating social identity. Long Grove, IL: Waveland Press. Bardhan, N. (2011)..Culture,communication, and third culture building in public relations within global flux. In N. Bardhan \& C. K. Weaver (Eds.), Public Relations in Global Cultural Contexts (pp. 77-107). New York, NY: Routledge.

B. Blanck, B.,Keil-Slavik, R., \& Loh, W. (Eds.). Ethik und Wissenschaften: Steitform fur Erwagungskultur, Sonderdruck, 11(3), 358-360.

Casmir, F. L. (1963). The Hitler I heard. The Quarterly Journal of Speech, 49, 8-16.

Casmir, F. L. (1973). International, intercultural communication: A annotated bibliography. Special communication module, ERIC Clearinghouse on Reading and Communication Skills.

Casmir, F.L. (Ed.) (1974-1976)..International and intercultural communication annual. Vols.1,2, 3. Falls Church, VA: Speech Communication Association.

Casmir, F. L.(1976).A multicultural perspective o human communication .In F. L. Casmir (Ed.), Intercultural and International Communication. Washington, DC: University Press of America.

Casmir, F. L.(1978).International and intercultural communication. Washington, DC: University Press of America.

.Casmir, F.L. (1984). Communication and development alternatives: Foundation for policy implementation designed to meet development needs of third-world nations.(US Department of State contract, May-November). Washington, DC: US Department of State.

Casmir, F. L. (1986). Conflict resolution: The role of human communication. Communicare, 5(2), 5-13.

Casmir, F. L. (1986). Foreign research fellow report: International and intercultural communication and negotiating. Navorsingbulletin Research Bulletin, 41-43.

Casmir, F. L. (1986). Reflections o the contemporary situation in South Africa. Libertas, (3-4), 35-42.

Casmir, F. L. (1987). Authority and power: The role of contemporary media systems in cultural change. RSA 2000: Dialogue with the Future, 9 (2), 29-34. 
Casmir, F. L. (1990). International negotiation: power and trust relationship. International and Intercultural Communication Annual, XIV, 40-55.

Casmir, F. L. (1990). Non-Western communication paradigms: The dilemma of how we know what we know. In Ermunterung Zur Freiheit: Retork and Erwachsenenbildung, Sprache und Sprechen, 23/24, 5163. Festschrift for Ilse Schweinsberg. Frankfurt, Germany: Scriptor.

Casmir, F. L. (1991). Introduction: Culture, communication, and education.Communication Education, 40(3).

Casmir, F. L. (1993). Third culture building: paradigm shift for international and intercultural communication.In S. A. Deetz (Ed.), Communication Yearbook (Vol. 16, 437-457). Newbury Park, CA: Sage.

Casmir, F. L. (1994).Building communication theories: socio/cultural approach. Hillsdale, NJ: Lawrence Erlbaum Associates

Casmir, F. L. (1994). Genug ist Genug. Unsere Sendung 1,5.

Casmir, F. L. (Ed.) (1995). Communication in Eastern Europe: The role of history, culture, and media in contemporary conflicts. Mahwah, NJ: Lawrence Erlbaum Associates.

Casmir, F. L. (1997b). Ethics, culture, and communication: A application of the third culture building model to international and intercultural communication. In F. L. Casmir (Ed.), Ethics in Intercultural and International Communication (pp. 89-118). Mahwah, NJ: Lawrence Erlbaum Associates.

Casmir, F.L. (Ed)(1997a).Ethics in intercultural and international communication. Mahwah, NJ: Lawrence Erlbaum Associates.

Casmir, F. L.(1999).Foundations for the study of intercultural communication based o a third culture building model. International Journal of Intercultural Relations, 23(1), 91-116..

Casmir, F. L. (1998). Interkulturelle Kommunikation als Prozess. In I. Jonach (Ed.), Interkulturelle Kommunikation, 15-26. Munich, Germany: Ernst Reinhardt, Verlag.

Casmir, F. L (1999).Some thoughts about ethics and intercultural communication. Newsletter: Intercultural Communication, 33, 1-3.

Casmir, F. L. (2000). Consensus and communication: A intercultural challenge. In F. Bensler, Hauptartihel: Ram Adhar Mall: Interkulturelle Verstandgung-Primat de Kommunication vor dim Kinsens? 337.

Casmir, F. L. (2001). Communicazione globale. Una prospettiva di communicazione interculturale. In C. Padovani (Ed.),Communicazione globale. Torino, ITALY: UTET Librería Srl. 
Casmir, F.L.,\& Asuncion-Lande, N. C. (1989). Intercultural communication revisited:

Conceptualization, paradigm building and methodological approaches In J. A. Anderson (Ed.),

Communication Yearbook (Vol. 12, 278-309). Beverly Hills, CA: Sage.

Casmir, F. L.\& Dervin, B. (1991).Communication in development. New York, NY: Harcourt Education.

Casmir, F. L.,Jue, L. \& Hue, Z. Y. (1987). Peking opera: Then and now. .World Communication.

Casmir, F. L.,\& Kweskin, K. J. S. (2001).Theoretical foundations for the evolution and testing of a chaos theory of communicating. World Futures, 57, 339-371.

Casmir, F.,L. \& Muir-Packman, H. (1999). Learning from the Euro Disney experience: A case study in international/intercultural communication. Gazette: The International Journal for Communication Studies, 61(6), 473-489.

Casmir, F. L. \& Swenson, J.(1998).The impact of culture-sameness, gender, foreign travel and academic background o the ability to interpret facial expression of emotion in others.Communication Quarterly 46(2).

Jain, N. C., Prosser, M. H.,\& Miller, M. H. (Eds.) (1974). Intercultural communication: Proceedings of the speech communication summer conference X. Falls Church, VA: Speech Communication Association.

Lee, P. W. (2006). Bridging cultures: Understanding the construction of relational identity in intercultural friendship. Journal of Intercultural Communication Research, 35(1), 3-22.

Lee, S. (2006). Somewhere in the middle: The measurement of third culture. Journal of Intercultural Communication Research, 35(3), 253-264.

Prosser, M.H. (Ed.)(1973, 1974).Syllabi in intercultural communication and social change. Charlottesville, VA: Department of Speech Communication, University of Virginia.

Prosser, M.H. (1978). The cultural dialogue: An introduction to intercultural communication. Boston, MA: Houghton Mifflin.

Simon, I. P.\& Baxter, L.A. (1993). Attachment-style differences in relationship maintenance strategies. Western Journal of Communication, 57, 416-430.

Stewart, E. C. (1972). Outline of intercultural communication. Washington, DC. ERIC Clearinghouse.

Appendix A: Casmir's Education

Doctor of Philosophy, The Ohio State University, Columbus, Ohio, 1961:.Major: Speech; Minors: Educational psychology, Mass Communication

Doctor of Philosophy dissertation: Hitler, study in persuasion. 
Master of Arts, The Ohio State University, Columbus, Ohio, 1955:.Major: Speech ;Minor: Educational psychology

Master of Arts Thesis: The Development of a test for the prediction of individual attitudes in speech. Bachelor of Arts, David Liscomb College, Nashville, Tennessee, 1950: .Major: Speech;Minor: Religion Abitur degree, high school education: completed in Berlin and Frankfurt, Germany, 1948.

Appendix B: Casmir's List of Accomplishments

Distinguished Professor Emeritus, of Communication, Pepperdine University, 1999

Distinguished Professor, Pepperdine University, 1994-1999

Professor of Communication, Pepperdine University, 1970-1994

Associate Professor of Communication Pepperdine College, 1962-1970

Assistant Professor of Communication Pepperdine College, 1957-1962

Instructor in Speech Communication, Pepperdine College, 1956-1957

Adjunct Faculty, Assistant and Associate Professor of Speech, San Fernando Valley State College, CSU, Northridge, 1961-1973

Adjunct Faculty East Los Angeles College, 1973-1974

Appendix C: Casmir's Selected Offices, Memberships, and Projects

Author of over 60 publications including over 20 books and annuals

Editorial Board at Gazette Communications

Editorial Board at Journal of Communication

Associate Editor at Communication Quarterly

Associate Editor at Journal of Critical Studies in Mass Communication

ICA Chairperson, Division V, Vice-President, ICA, 1997-1999

Coordinator, International Studies Major at Pepperdine University

Faculty Advisor, Sigma lota Rho, International Studies Honor Society at Pepperdine University

Chairperson, Council for International Studies at Pepperdine University

Chairperson, Faculty Admissions and Scholarship Committee at Pepperdine University 
Teacher of the Year, Alumni Association, Pepperdine University, 1985

International Consulting and Teaching experiences in Germany, India, Singapore, Sri Lanka, Thailand, Malaysia, Australia, New Zealand, France, Japan, Austria and China

International Program for Developmental Communication, Member, US Delegation, Paris, May 1984.

Second World Conferences on Cultural Policies, Mexico City, Senior Advisor, United states Delegation. A White House appointment: July 26-August 6, 1982.

Coordinating Vice President for North America, SIETAR International, 1982-1983

Lectures: "Radio-TV in the USA," "Speech Education in America," Sociological Problems in the US," Rhetoric and Politics," "Recent Developments in the Study of Oral Communication" (lectures in German and English), 1965-1966

International Consulting and Teaching experiences in Germany, India, South Africa, Singapore, Sri Lanka, Thailand, Malaysia, Australia, New Zealand, France, Japan, Austria and China.

Appendix D: Casmir's Grants

"American Journalists and Their Social Interaction," Pepperdine University, Malibu, California, 1986.

US Department of State contract; development of review and study: "Communication-in-development alternatives: Foundations for policy implementations, designed to assist in meeting developmental needs of Third World Nations," May-November, 1984.

"An attitude study of entering freshmen," Pepperdine University, Malibu, California (Replication of 1935 Bennington College Study), 1973.

"A study for the Food and Drug Administration (FDA No. 67-57),"Study of critical attitudes and procedures in various health professions" (drug abuse).An interview study, 1968. 